\title{
ACCESSIBILITY ASSESSMENT OF EMERGENCY VEHICLES IN TOKYO METROPOLITAN AREA AFTER A LARGE EARTHQUAKE
}

\author{
M. Kishimoto ${ }^{1, *}$, T. Osaragi ${ }^{1}$ \\ ${ }^{1}$ Tokyo Institute of Technology, 2-12-M1-25, Ookayama, Meguro-ku, Tokyo 152-8550, Japan \\ - (kishimoto.m.ac, osaragi.t.aa)@m.titech.ac.jp \\ Commission IV, WG IV/10
}

KEY WORDS: Large Earthquake, Property Collapse, Route Choice Behaviour, Accessibility Assessment, Emergency Vehicles, Local Accessibility

\begin{abstract}
:
At the time of a large earthquake, property collapse (e.g., building collapse and street blockage) will obstruct emergency activities (e.g., firefighting activity and ambulance service) and cause the expansion of secondary damage. For reducing the secondary damage of a large earthquake, it is important to assess the accessibility of emergency activity under property collapse. However, the accessibility index, which can evaluate the emergency activity considering the effect of property collapse, is not developed nor applied in actual urban area. In this paper, we propose the street network accessibility: indices of assessing the movement of emergency vehicles. Then, we construct a simulation model that describes property collapse and the movement of emergency vehicles. Performing the simulation in Tokyo Metropolitan Area, we evaluate the damage of each building/street and assess the street network accessibility after a large earthquake. Finally, analysing the relationships among indices, we indicate that it is important to evaluate the street network accessibility from multiple viewpoints.
\end{abstract}

\section{INTRODUCTION}

In recent years, we have experienced many natural disasters in Japan. As it is predicted that there is a $70 \%$ possibility of an earthquake directly hitting Tokyo within the next 30 years, it is assumed that large-scale disaster will continue to happen (Headquarters for Earthquake Research Promotion, 2017).

At the time of a large earthquake, it is presumed that the street blockage, which is caused by building collapse, will obstruct the emergency activity (e.g., firefighting activity and ambulance service) and cause the expansion of secondary damage. For reducing the secondary damage, it is especially important to ensure that emergency vehicles can arrive to the destination within the first 72 hours after a disaster happened (FEMA, 2011). For ensuring the certainty of emergency activity, we need to assess the accessibility of emergency activity (e.g., arrival status, travel distance, and the safety of the movement) under the property collapse (e.g., street blockage and building collapse).

A large body of studies have been carried out to assess the accessibility of emergency activity under disaster situation. For instance, Iida (1999) proposes road network reliability $R$, which is a probability that there exists at least one path without disruption or heavy delay to a given destination within a given time period. Although this index can evaluate arrival status of emergency activity, it cannot assess the movement of emergency vehicles itself. Moreover, they did not apply this index in actual urban area. Tokyo Metropolitan Government (2018) estimated Community Earthquake Risk in Tokyo Metropolitan Area. Community Earthquake Risk is combined risk of property collapse risk (the number of collapsed building and burned-down building) and emergency response difficulty (the easiness of emergency activity conduction). Since they estimate the risks with simplified method, the effects of property collapse on emergency activity is not considered enough. As above, few studies evaluate accessibility of emergency activity by making full use of information obtained by a detailed simulation model, which estimates property collapse of each building / street and the movement of emergency vehicles. Analysing the movement of emergency vehicles from multiple viewpoints, it is expected that we can evaluate the influence of property damage on emergency activities after a large earthquake more in detail.

In this paper, we propose a novel index, which evaluates the safety of the movement of emergency vehicles. First, we define the street network accessibility composed of three indices for assessing the movement of emergency vehicles. Then, we construct a simulation model, which consists of the following two sub-models: (I) property collapse model to describe building collapse and street blockage; and (II) emergency behaviour model. In emergency behaviour model, emergency vehicle chooses the time-dependent shortest route considering the location of street blockage at the time of a large earthquake. Finally, using the simulation model, we evaluate the street network accessibility in Tokyo Metropolitan Area after a large earthquake. Furthermore, analysing the relationships among indices using spatial distributions and scatter diagrams, we indicate the importance of accessibility assessment of emergency activity from multiple viewpoints.

\section{ESTIMATION METHOD OF STREET NETWORK ACCESSIBILITY}

\subsection{Definition of Street Network Accessibility}

In this paper, we evaluate the street network accessibility with following indices: (1) Local Accessibility $(L A)$; (2) Travel Time Increment (TTI); and (3) Local Access Possibility ( $L A P)$.

Local Accessibility $(L A)$ is the ratio of emergency vehicles which can access to buildings in total (defined below).

\footnotetext{
${ }^{*}$ Corresponding author
} 


$$
L A_{\mathrm{a}}=1-\frac{\sum_{i \in R_{\mathrm{a}}} s_{i} \cdot \delta_{i}}{\sum_{i \in R_{\mathrm{a}}} s_{i}}
$$

where $R_{\mathrm{a}}$ is a set of buildings in region a, $s_{i}$ is the area of building $i\left(\mathrm{~m}^{2}\right), \delta_{i}$ is the arrival status with a value of 1 when emergency vehicle can access to building $i$ and 0 when not.

Since $L A$ is the index, which only evaluates the arrival status of emergency activity, we propose Travel Time Increment (TTI) and Local Access Possibility $(L A P)$ to assess the efficiency and the safety of the emergency vehicles' movement. In this paper, we define the efficiency as the ability of emergency vehicles to reach the destination without taking a long detour and the safety as the access possibility that emergency vehicles can access to each building under different case of property collapse.

TTI is increment ratio of travel time between the cases with/without street blockage (defined below). By this index, we can evaluate the efficiency of emergency vehicles' movement.

$$
\operatorname{TTI}_{a}=\frac{\sum_{i \in R_{a}} \delta_{i} \cdot T_{i}^{\prime} / T_{i}}{\sum_{i \in R_{a}} \delta_{i}}
$$

where $R_{\mathrm{a}}$ is a set of buildings in region a, $T_{i}$ is travel time to building $i$ at normal period (min), $T^{\prime}{ }_{i}$ is travel time to building $i$ after a large earthquake (min), $\delta_{i}$ is the arrival status with a value of 1 when emergency vehicle can access to building $i$ and 0 when not.

In this paper, we propose $L A P$ as the index to evaluate the safety of emergency vehicles' movement to building $i$ after a large earthquake as follows:

$$
\begin{aligned}
& L A P_{\mathrm{a}}=1-\frac{\sum_{i \in R_{a}} s_{i} \cdot p_{i}}{\sum_{i \in R_{a}} s_{i}}, \\
& p_{i}=\prod_{j \in L_{i}}\left(1-q_{j}\right),
\end{aligned}
$$

where $R_{\mathrm{a}}$ is a set of buildings in region a, $s_{i}$ is area of building $i$ $\left(\mathrm{m}^{2}\right), p_{i}$ is access possibility in which emergency vehicles can access from emergency transportation roads to building $i, L_{i}$ is a set of streets on the time-dependent shortest route to building $i$, and $q_{j}$ is probability that street $j$ is blocked.

\subsection{Overview of Emergency Activity Simulation Model}

To evaluate the street network accessibility, it is necessary to estimate the movements of emergency vehicles at the time of a large earthquake. Figure 1 shows an overview of the simulation model that we developed. This model consists of the following two sub-models: (I) property collapse model to describe building collapse and street blockage; and (II) emergency behaviour model.

2.2.1 Property Collapse Model: We estimate the property collapse (building collapse and street blockage) to consider its effect on the emergency activity.

The probability of building collapse $P_{\mathrm{R}}(P G V)$ is estimated from the value of Peak Ground Velocity $(P G V)$, the structure material (wood, reinforced-concrete, or steel) and the construction year of a building (Murao and Yamazaki, 2000).

$$
P_{\mathrm{R}}(P G V)=\phi\left(\frac{\ln (P G V)-\lambda}{\xi}\right),
$$

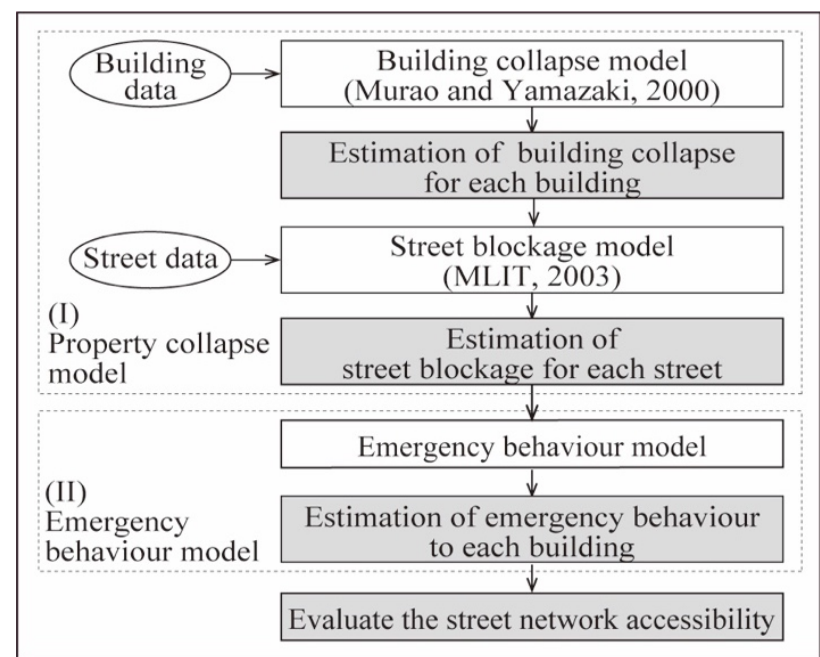

Figure 1. Overview of simulation model

where $\phi()$ is a cumulative distribution function, $\lambda$ and $\zeta$ are the average and the standard deviation of $\ln (P G V)$, respectively; they vary according to the structure material and the construction year of a building. Then, we determine the state of a building (collapsed or not collapsed) by comparing the probability of building collapse $P_{\mathrm{R}}(P G V)$ with a generated uniform random number.

We use the model proposed by MLIT (2003) to estimate the blockage of streets. The probability of street blockage $P_{b}(W)$ on a street of width $W(\mathrm{~m})$ is estimated as the probability that buildings along the street generate debris which blocks a street.

$$
P_{b}(W)=1-\prod_{i \in G}\left(1-f_{i}(W)\right),(6)
$$

where $f_{i}(W)$ is the probability that the debris of collapsed building $i$ outflows to the street (Figure 2 (iii)) and $G$ is the set of roadside buildings that generate the debris. Hirokawa and Osaragi (2016) describe the details of these models.

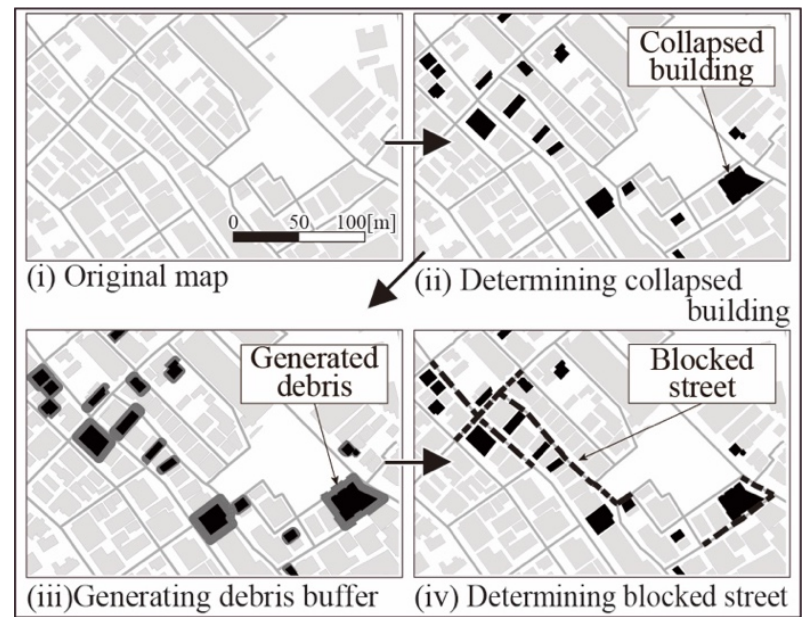

Figure 2. Estimation of property collapse 
2.2.2 Emergency Behaviour Model: Figure 3 shows the overview of the emergency behaviour model. We construct the emergency behaviour model of activities such as firefighting activity or ambulance service. In these activities, emergency vehicles are required to arrive at a destination as soon as possible. Therefore, we assume that emergency vehicles choose the timedependent shortest route to a destination.

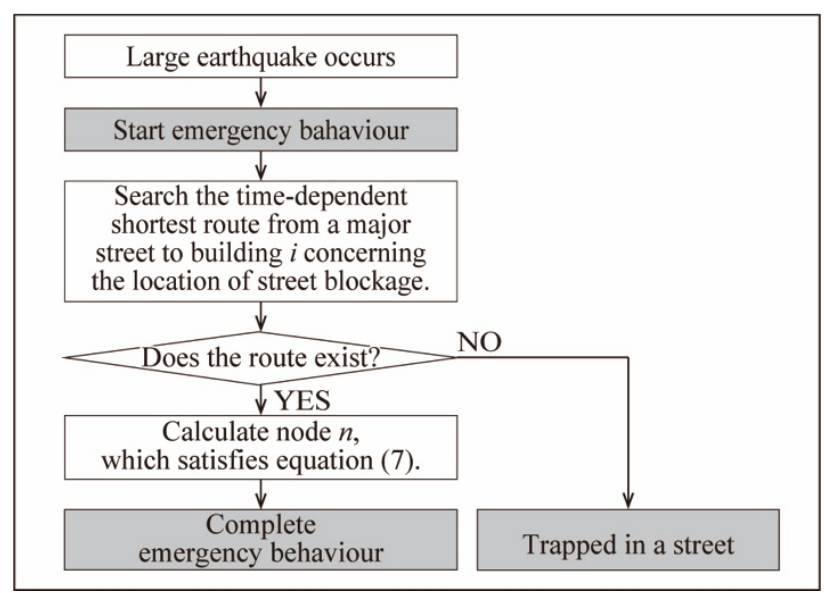

Figure 3. Overview of the emergency behaviour model

We describe the emergency behaviour of each vehicle that moves from any of major streets to a destination ${ }^{1}$. It is assumed that we know the street network and the location on street blockages initially. We use Dijkstra's algorithm to search the timedependent shortest route (Dijkstra, 1959).

Although emergency activity is mainly conducted by emergency vehicle (emergency activity), it is also conducted by emergency responder (pedestrian activity) in following situations;

- When it is difficult to access to a destination only by an emergency vehicle.

- When it is faster to access to a destination by an emergency responder than an emergency vehicle.

Since it is unrealistic to change the activity types (vehicle activity and pedestrian activity) repeatedly, we assume the change of activity type is done at most once. Emergency activity is conducted by minimizing the travel time $\left(T_{i}\right)$ from any of major streets to building $i$. The travel time $\left(T_{i}\right)$ is described as the following Equation 7.

$$
T_{i}=T_{n}+t_{n i},
$$

where $T_{i}$ is the travel time from any of major streets to building $i$, $T_{n}$ is the shortest travel time from any of major streets to node $n$ by emergency vehicle, $t_{n i}$ is the shortest travel time from node $n$ to building $i$ by emergency responder, and $n$ is any node in region a.

The transportation speed of each street is defined with activity types (vehicles activity and pedestrian activity) and width of street $^{2}$.

\footnotetext{
${ }^{1}$ The aim of this paper is to evaluate the accessibility of emergency activity in areas surrounded by emergency transportation roads. Therefore, it is assumed that the emergency transportation road will not be blocked and its influence is excluded from the discussion of this paper.
}

Since we consider the influence of property collapse at the time of a large earthquake, emergency vehicles are trapped in a street, or forced to take a large detour during emergency behaviour due to blocked streets. It is also presumed that they are trapped in a street if there are no routes to a destination.

\section{CASE STUDY: ACCESSIBILITY ASSESSMENT IN TOKYO METROPOLITAN AREA}

\subsection{Study Area and Assumptions in Simulation}

Performing an emergency activity simulation, we estimate the property collapse in Tokyo Metropolitan Area (Figure 4), and evaluate the street network accessibility from emergency transportation roads ${ }^{3}$ to each building. Since the purpose of this paper is to evaluate the street network accessibility, we do not consider the population distribution in the study area.

To clarify the differences of simulation results among areas, the street network accessibility is averaged in a spatial unit surrounded by emergency transportation roads (Figure 4).

The building data used in simulations are based on the land use survey conducted by Tokyo Metropolitan Government in 2011, and the street data (as of 2014) are provided by the Tokyo Fire Department. Some attributes of buildings and streets are prepared beforehand (Figure 4) (Hirokawa and Osaragi, 2016). We set transportation speed of each street referring to laws and regulations (Table 5) (MLIT, 2018; Japan Society of Traffic Engineers, 1984; Japan Road Association, 1970).

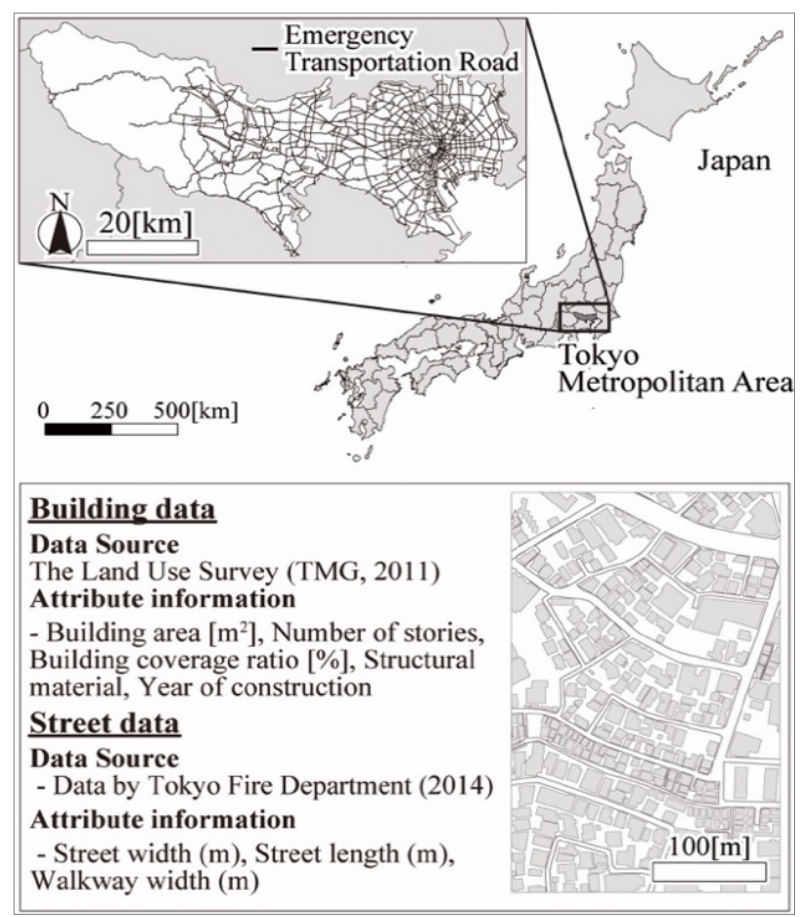

Figure 4. Study Area

${ }^{2}$ In the emergency behaviour model, the congestion of each street or the existence of collapsed building's debris on each street are not considered.

${ }^{3}$ To ensure passage of emergency vehicles immediately after the disaster, MLIT designate national highway, general national roads, and some major roads as emergency transportation road. 


\begin{tabular}{ccc}
\hline & $\begin{array}{c}\text { Vehicle } \\
\text { activity }\end{array}$ & $\begin{array}{c}\text { Pedestrian } \\
\text { activity }\end{array}$ \\
\hline $12.0 \mathrm{~m} \leqq W$ & $60.0 \mathrm{~km} / \mathrm{h}$ & $5.0 \mathrm{~km} / \mathrm{h}$ \\
$6.0 \mathrm{~m} \leqq W<12.0 \mathrm{~m}$ & $40.0 \mathrm{~km} / \mathrm{h}$ & $5.0 \mathrm{~km} / \mathrm{h}$ \\
\hline$W<6.0 \mathrm{~m}$ & $20.0 \mathrm{~km} / \mathrm{h}$ & $5.0 \mathrm{~km} / \mathrm{h}$ \\
\hline
\end{tabular}

Table 5. Transportation speed on a street $\mathrm{j}$, whose width is $\mathrm{W} \mathrm{m}$.

To consider the effects of the variance of property collapse in each case, we prepare 100 cases of property collapse and execute a simulation for each case to evaluate the street network accessibility. To exclude the influence of the ground characteristics and the epicenter location, Peak Ground Velocity (PGV) is fixed at $66 \mathrm{~cm} / \mathrm{s}$.

\subsection{Spatial Distribution of Property Collapse Indices}

Figures 6,7 , and 8 show the spatial distribution of building collapse risk (the ratio of collapsed buildings to total number of buildings) and street blockage risk (the ratio of blocked streets to total number of streets). The value of each index is high in the eastern part of Tokyo, especially in densely built-up wooden residential area (areas 1,2, and 3). This is because these areas tend to have an unfavourable local environment from the viewpoint of vulnerability to a large earthquake. For instance, there is a dense distribution of old wooden buildings and narrow streets (Figure 9).

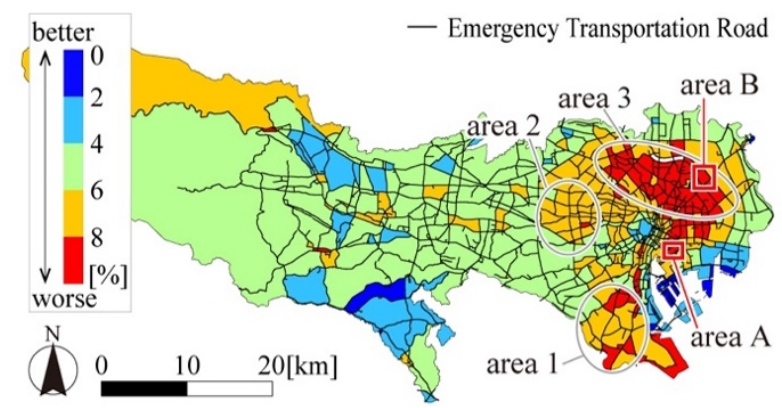

Figure 6. Spatial distribution of building collapse risk

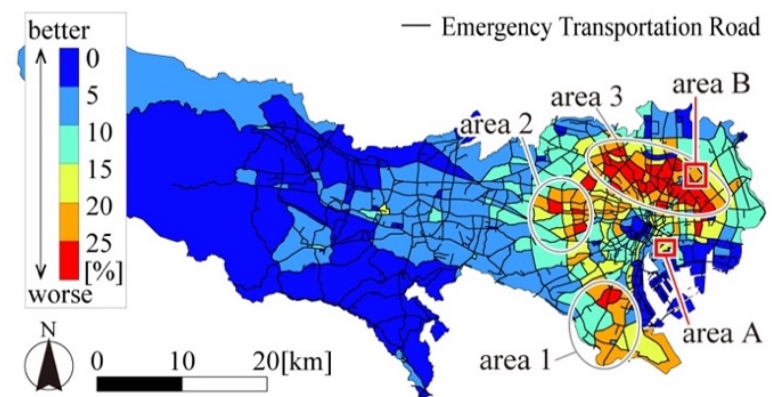

Figure 7. Spatial distribution of street blockage risk (emergency vehicles cannot pass, passible width: $4 \mathrm{~m}$ )

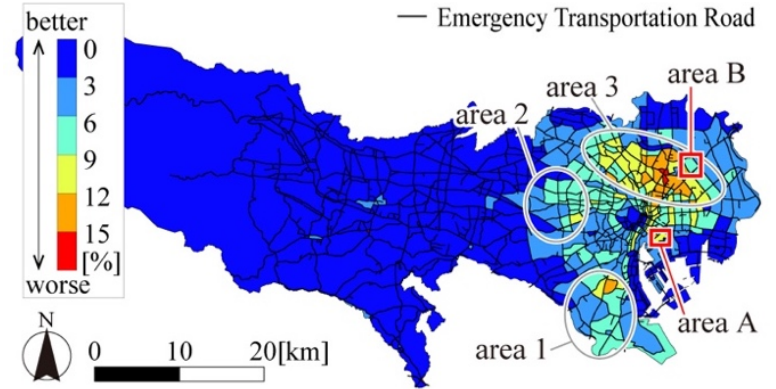

Figure 8. Spatial distribution of street blockage risk (emergency responder cannot pass, passible width: $0 \mathrm{~m}$ )

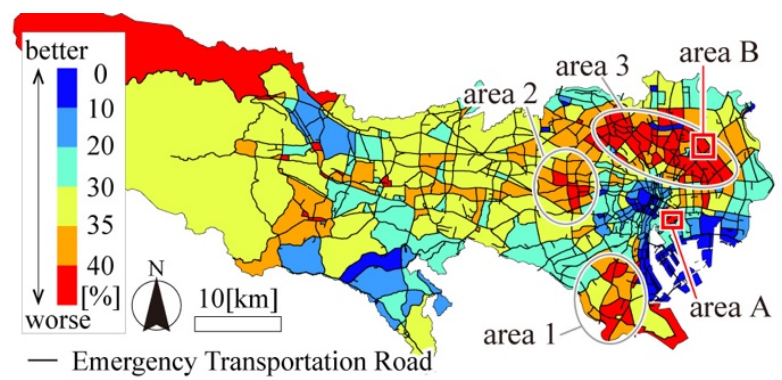

Figure 9. Spatial distribution of old wooden building ratio; the ratio of old wooden building ratio to total number of buildings

\subsection{Spatial Distribution of Street Network Accessibility}

Figures 10, 11, and 12 show the spatial distribution of the street network accessibility. $L A$ remarks high value in all parts of Tokyo Metropolitan Area (Figure 10). In other words, emergency vehicles can access to the most parts of Tokyo. On the other hand, $T T I$ and LAP remark worse value in eastern part of Tokyo, especially in areas 1, 2, and 3 (Figures 11 and 12). In these areas, street blockage risk also indicates low value (Figures 7, 8, 13, and 14). It shows the difficulty of securing the street network accessibility in areas with high property collapse risk.

As mentioned in Section 2, TTI and $L A P$ are the indices to assess the movement of emergency vehicles, whereas $L A$ is the index to evaluates the arrival status of emergency activity. By $T T I$ and $L A P$, we can assess the movement of emergency vehicles from two viewpoints; the efficiency and the safety. Figure 16 shows the spatial distribution of normalized residuals from single liner regression model of $L A P$. Values of normalized residual tend to be negative in areas 1,2, and 3(e.g., area B) and positive in the central area of eastern part of Tokyo (e.g., area A). Namely, compared with the value of TTI, LAP remarks relatively good value in area $A$ and bad value in area $B$. That is, since emergency vehicles approach the destination via streets with high street blockage risk, the safety of the emergency vehicles' movement is worse in area B than area A. In other words, analysing the movement of emergency vehicles not only by $T T I$ but also by $L A P$, it is possible to evaluate the influence of property damage on emergency activities after a large earthquake more in detail. 


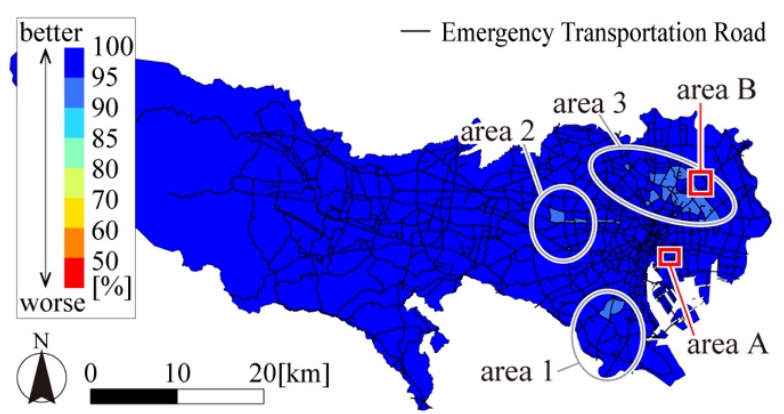

Figure 10. Spatial distribution of $L A$

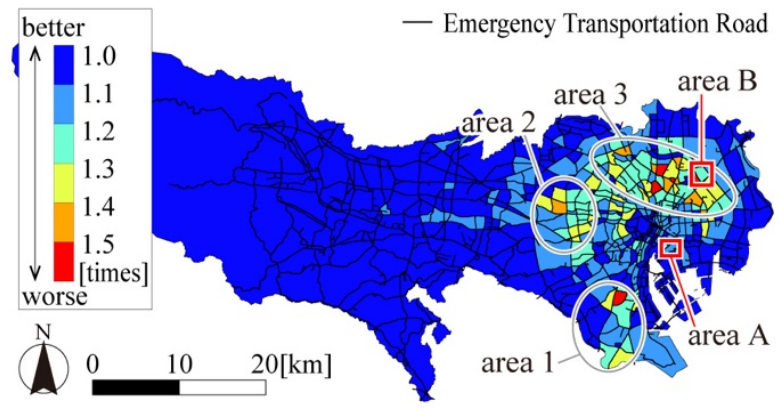

Figure 11. Spatial distribution of TTI

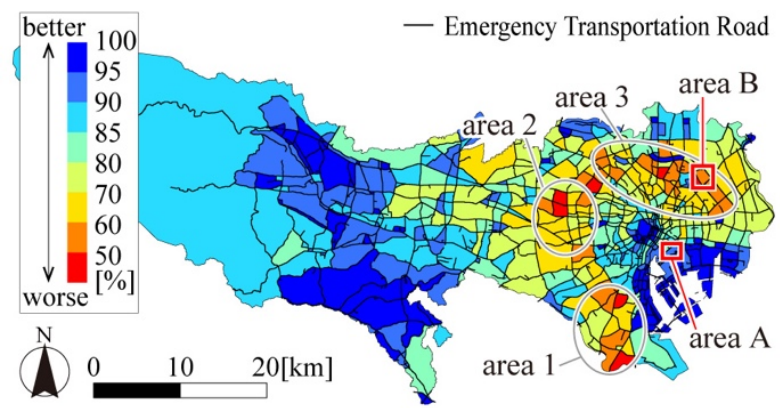

Figure 12. Spatial distribution of $L A P$

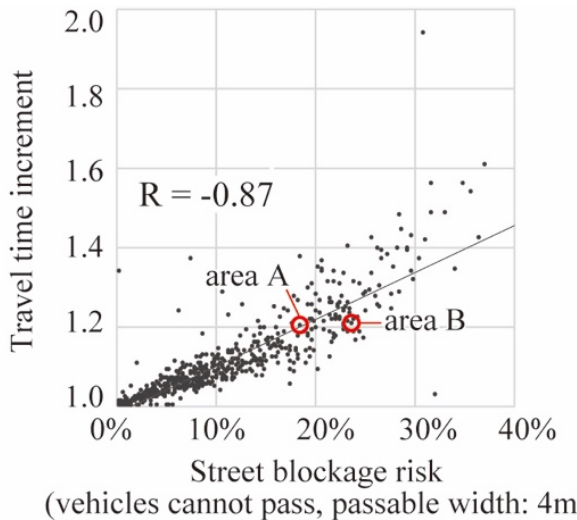

Figure 13. Comparison of street blockage risk and TTI

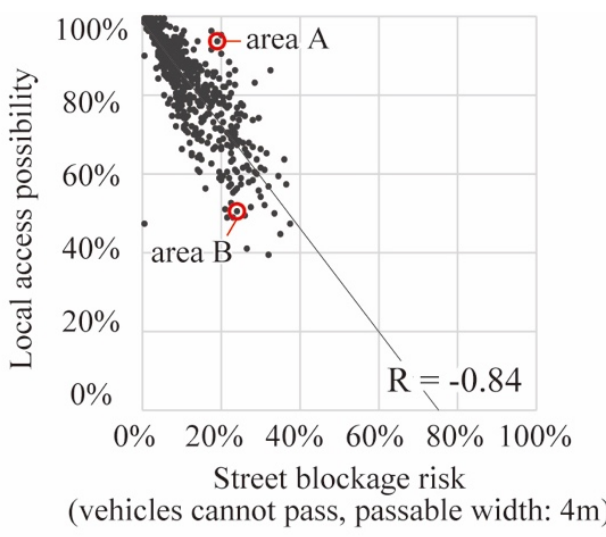

Figure 14. Comparison of street blockage risk and $L A P$

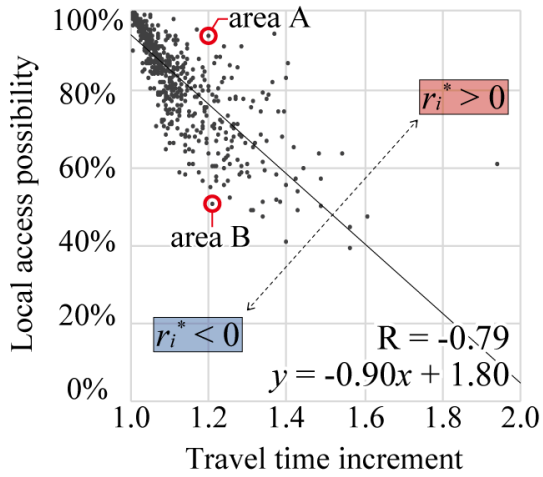

*Values of standardized residuals

Figure 15. Comparison of TTI and $L A P$

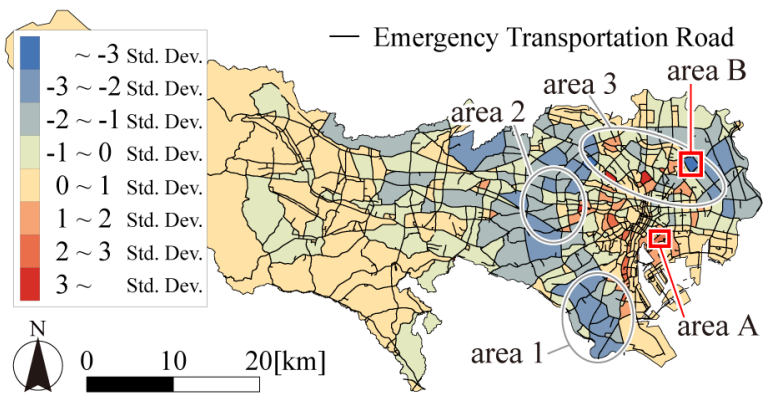

Figure 16. Spatial distribution of standardized residuals from simple liner regression model of $L A P$

\section{SUMMARY AND CONCLUSIONS}

To assess the movement of emergency vehicles under the property collapse, we proposed the street network accessibility and constructed a simulation model that describes property collapse and the movement of emergency vehicles. In this model, we described the movement of emergency vehicles from any major streets to a building. Emergency vehicles were assumed to choose the time-dependent shortest route to a building with the location of street blockages. Using this model, it was possible to describe the movement of emergency vehicles including those trapped in a street or forced to take a large detour due to blocked streets.

Performing the simulation in Tokyo Metropolitan Area, we evaluated the damage of each building/street and calculated property collapse risk and the street network accessibility for each spatial unit surrounded by emergency transportation roads. 
Furthermore, we analysed the relationships among indices using spatial distributions and scatter diagrams. Local Accessibility $(L A)$ remarked high value in all parts of Tokyo. On the other hand, Travel Time Increment (TTI) and Local Access Possibility $(L A P)$ remarked worse value in the eastern part of Tokyo, especially in areas with high street blockage risk. Furthermore, analysing the movement of emergency vehicles from multiple viewpoints, by $T T I$ and $L A P$, we demonstrated that it was possible to evaluate the influence of property damage on emergency activities after a large earthquake more clearly.

In future work, we will attempt to analyse the relationship between the street network accessibility and local characteristic and identify appropriate strategies to improve the street network accessibility, which differ according to the local environment of each area.

\section{ACKNOWLEDGEMENTS}

The authors would like to express our sincere appreciation to Tokyo Metropolitan Government and Tokyo Fire Department for their generous cooperation. This work was supported by JST Program on Open Innovation Platform with Enterprises, Research Institute and Academia (OPERA). We also appreciate the valuable comments from anonymous reviewers and T. Oki at Tokyo Institute of Technology.

\section{REFERENCES}

Dijkstra, E. W., 1959. A note on two problems in connexion with graphs. In: Numerische Mathematik, Vol. 1, pp. 269-271.

Federal Emergency Management Agency (FEMA), 2011. FEMA Strategic Plan: Fiscal Years 2011-2014. https:// www.fema.gov/media-library-data/20130726-1823-25045-3227 /fema_2011_2014_strategic_plan.pdf (13 May 2018).

Headquarters for Earthquake Research Promotion, 2017. List of long-term evaluations (in Japanese), https://www.jishin.go.jp/ main/choukihyoka/ichiran.pdf (7 May 2018).

Hirokawa, N. and Osaragi, T., 2016. Earthquake disaster simulation system: Integration of models for building collapse, road blockage, and fire spread. In: Journal of Disaster Research, Vol. 11, No. 2, pp. 175-187

Iida, Y., 1999. Basic Concepts and Future Directions of Road Network Reliability Analysis. In: Journal of Advanced Transportation, Vol. 33, No. 2, pp. 125-34.

Japan Road Association, 1970. Commentary on Japanese Road Structure Ordinance (in Japanese), Maruzen.

Japan Society of Traffic Engineers, 1984. Traffic Engineering Handbook 1984 (in Japanese), Gihodo Shuppan.

Ministry of Land, Infrastructure and Transport (MLIT), 2003. Developments of technology and evaluation index of disaster mitigation for planning local areas (in Japanese). http:// www.nilim.go.jp/lab/jdg/soupuro/0.pdf

Ministry of Land, Infrastructure and Transport (MLIT), 2018. Road Structure Ordinance (in Japanese), http://elaws.egov.go.jp/search/elawsSearch/elaws_search/lsg0500/viewConte nts?lawId=345CO0000000320_20150801_000000000000000

(27 April 2018).
Murao, O. and Yamazaki, F., 2000. Development of fragility curves for building based on damage survey data of a local government after the 1995 Hyogoken-nunbu earthquake. In: Journal of Structural and Construction Engineering, No. 527, pp. 189-196 (in Japanese).

Tokyo Metropolitan Government, 2018. Community earthquake risk assessment study (in Japanese). http://www.toshiseibi. metro.tokyo.jp/bosai/chousa_6/home.htm (7 May 2018). 